AGORA International Journal of Juridical Sciences, http://univagora.ro/jour/index.php/aijjs

ISSN 1843-570X, E-ISSN 2067-7677 No. 2 (2017), pp. 124-132

\title{
BEYOND THE LAW. THE CPD MODEL FOR THE PROFESSIONAL DEVELOPMENT OF FUTURE TEACHERS.
}

\section{Refrigeri}

\author{
Prof. Luca Refrigeri \\ Department of Humanities, Social Sciences and Education \\ University of Molise (Italy) \\ e-mail: luca.refrigeri@unimol.it
}

\begin{abstract}
The paper aims to describe the experimental project of the adjustment pathway to school that was developed at the Primary Education Degree of the University of Molise. The project started from the model of the Continuing Professional Development (CPD) typical of the Anglo-Saxon professional culture that does not find a specific application in schools system of teacher training, expecially in Italy, and developed from the scholar prof. Stefano Bonometti. The project aims to develop the students' culture of lifelong learning education, starting from universities education by developing a personal plan of professional development through typical methods of the CPD. Particularly, students of the fifth year, the final year of the degree course, will start a process of reflection of acquired skills, while those of the second year, the first year of traineeship, will start the process of training and monitoring of their acquisition skills during the course. The project after a period of stop is starting again in this year.
\end{abstract}

KEY WORDS: Continuing Professional Development, teacher training, learning environment, primary education degree.

\section{INTRODUCTION}

As reported in a previous paper traditionally the development of the professional identity of teachers is an activity carried out by many scholars concerned with pedagogy and didactics. It does not seem, however, there is no one in Italy, but perhaps also in many other European countries, using model of Continuing Professional Development to develop the professional identity in other professional fields. Some years ago we started togheter to prof. Stefano Bonometti with a pilot project, still undergoing implementation, with the aim of promoting the professional identity of the future teacher importing a typical model generally used in company and private organizations context. The framework comes from a perspective of lifelong learning, proposing strategies and opportunities for empowerment, through the activation of a professional project in 
continuous development using the Continuing Professional Development model with students of the Primary Education degree of the University of Molise, the future primary teachers. The key assumptions of this particular educational path are the learning from experience and reflection on it, trigger a project dimension in a lifelong learning perspective, referring to build professional identity. This perspective highlights the context socio-cultural environment (Engeström, Sannino 2010), and encourages a reflective attitude that leads the students to observe their actions in the school, context of work. The aim is to support the acquisition of a strong identity as a teacher and learning capacity of the continuous development of their professionalism. The theoretical framework of experimentation lead back to UK studies on CPD and their application in the contest of teachers training and supports the ability to build relationships of trust that can strengthen the sense of organizational citizenship.

\section{BASIC PRINCIPLES OF CONTINUING PROFESSIONAL DEVELOPMENT}

The Institute of Personnel and Development of the United Kingdom defines CPD as a constant keeping up-todate (updating) of the professional knowledge throughout the entire working life through systematic, informal or self-directed learning models. A further definition, affirmed by the Royal Town Planning Institute and confirmed by the CPD Certification Service of London, indicates CPD as "the systematic maintenance, improvement and broadening of knowledge and the development of personal qualities necessary for the execution of professional and technical duties throughout the practitioner's working life" (Peel, 2005). The definition emphasizes CPD as s systematic process within the professional development in order to maintain, increase and develop knowledge, skills and personal qualities throughout one's working life. The key features can be summarized in four expressions: continuity through the whole working life, professional requirements, personal qualities, systematic nature of the process. The approach to CPD requires: - the mutual linking between organisational strategies and individual needs; - the view of human resource management as an investment and not simply as a cost; - the enhancement of learning on the job, taking care of the effective transfer of learning in the workplace; - the planning and designing of training activities at different levels of formality (Eraut, 2000) to support learning processes that correspond to the concept of Personal Development Plans (PDPs).

The key features of the definition which distinguish the CPD are represented by the continuity of learning throughout the working life, the maintenance of high-level quality and competence of professionalism, the development of knowledge, skills and personal qualities, the planning that ensures a systematic process. These characteristics allow CPD to assume a fundamental role to facilitate the accreditation process of professionals and to support the personal professional development and of the group.

\section{WORKPLACE LEARNING, LEARNING ENVIRONMENT AND LEARNING FROM OTHER}

The first requirement is considering the workplace as an opportunity of Workplace Learning in continuum with university context. The workplace is not only the place where intellectual or practical activities carried out but also the place site with continuing learning opportunities. This means that the range of activities that take place, daily, in the workplace provide learning opportunities supported by actions that Eraut (2000) lists as follows: - learning from doing routine work activities; - learning on the job through a learning plan with the involvement of a certain variety of roles connected to the own role; - informal and occasional learning through meetings with other workers; - both informal and formal learning through the reflection on artefacts in the workplace. This means that people, the work activities, the materials and the equipment all become learning 
resources. The analysis conducted by A. Fuller, L. Unwin (2004) leads to identify a list of factors that shape the environment according to an Expansive Learning approach. This list is based on the antinomy between "expansive-restrictive" which, in the opinion of the authors, allows a better understanding of the actions to be adopted to define a learning environment. The comparison between the two methods emphasizes the different actions that will be needed to create the learning environment. Between these two extremes, actually in the continuum are identified the most effective practices for the different organizational contexts. Focusing on the "expansive" approach the above mentioned research has identified a certain number of actions that allow the realization of an Expansive Learning Environment. Among them, the most significant are: the participation and commitment to diverse communities of practice in order to favour the exchange of different competencies and skills. The attention is also paid to the realized learning experiences (or to realize) in other organizational contexts, overcoming the insurmountable "fear of being copied". This mental approach, if related to a genuine professional interest, supports and strengthens the organizational identity.

Evans et al. (2006) also argue that both formal education and informal learning taking place in the immediate workplace community are essential, thus extending the apprenticeship learning advocated by Lave and Wenger. Second, they offered an analytical continuum, acknowledging the context-specific nature of learning in individual classrooms and schools, in a way that Lave and Wenger's work did not. Third, Evans et al.'s work challenged ideas of a linear journey from novice to expert as being too simplistic. This framework offered us a way of evaluating workplaces, although in our study from the BTs' perspectives only. It was not designed however to offer a way of understanding teachers' responses to such environments. Another requisite for the start of CPD is given by what Eraut defines learning from others through peer learning (peer to peer) as well as learning from experts or significant others (tutoring). In a research conducted by M. Eraut (2007), that evidences some approaches that support Expansive Learning Environment (Fuller \& Unwin, 2004), the persons interviewed affirm that "learning from others" in the working context represents one of the most significant methods for professional development. This approach can be placed, according to Eraut, in the continuum where on one side there is the individual dimension and on the other the organizational dimension. Referred to the individual one, the fulcrum of "learning from others" is the importance of the tacit knowledge of everyone to share daily with the colleagues while carrying out one's profession. On the opposite side of the continuum in the organizational dimension the reference point of learning is mainly based on "propositions and written documents" which are progressively more formalized. According to Eraut, "the learning process started by the worker moves within this continuum in accordance with some central reference points: the own personal dispositions and the manager's support" (Ibidem, p. 36). In other words, the effectiveness of a learning environment that gives value to the support and mutual help is fully implemented if it is hold up, on one hand, by the personal motivation and the willingness to a social participation and, on the other hand, by the workplace configuration and the organizational culture that encourages and stimulates co-participation and collaboration. The vast majority of teacher trust that there is still a lot to be discovered and developed for consistently brilliant teaching. Istitute for Leanring write that «evidence shows that the CPD most likely to lead to the desired impact is based on learning from others - from shared resources, from peer support and working together and through formal and informal networks. Organisations with a real interest in developing teaching and learning also identified working in teams, mentoring, and engaging in action research as most likely to lead to brilliant teaching and training » (IfL, 2010). 
A. D. Ellinger and M. Cseh (2007), who identified a certain number of factors, such as behaviour and communication that facilitate the learning process of the participants, have also investigated the importance of the personal dimension for the creation of working environments. The authors indicate the listed factors as behaviours that experts can adopt to facilitate the learning, mentioning managers and responsible persons in charge, by improving confronting techniques and forms of co-participation starting from daily experiences. A recent Irish study (Morgan, 2009), highlighted that life beyond school is important in helping novice professionals to cope with new workplace demands, both in terms of emotional and informational support. It is for these reasons that we have investigated the role of personal networks to help us understand how support is offered and used by Beginner Teachers. (Fox et ali, 2010). The study of Fox evidence that the Beginner Teachers found schools as largely expansive learning environments in terms of support planned into their induction or training or as opportunities with which the teachers could engage informally. This represents the strong invitational nature of these schools as learning environments (Billett, 2001). This should not be entirely surprising given that the schools, at least in the pre-service year, were selected by the University as suitable environments into which to place training teachers.

\section{TEACHER'S PROFESSIONAL DEVELOPMENT THROUGH THE CPD APPROACH}

«Brilliant teaching and training does not happen by accident. It is created through careful thinking ahead and preparing teaching or training to meet the needs of each learner; the level and kind of course; and the range of outcomes and progression needed» (Fazaeli T., 2010). Become brilliant teachers requires a process of gradual integration into communities, as referred professional, this is done through a dual path of professionalism: the first relates to specific disciplinary skills, the second path regards teaching methodologies that promotes effective teaching practice. The application of CPD can have three different approaches (Bonometti, 2013) that represent different levels of formalization of the process. The first approach, defined "certified", has a "standardized" structure with the designing of the process according to the rules and the culture of a specific profession. In fact, the scientific community and the "professional group" can determine the development-phases and the steps of continuing updating which are essential to ensure a certain level of professionalism. The development of the process and the sharing agreement of the updating according to the rules guarantee public accreditation to the professional (in some cases with legal value). In such a case, the process of professional development (CPD) becomes a sort of obligation while carrying out one's profession and the lack of respect for the operational guidelines may produce sanctions by the "professional group". The risk that may occur with this approach is to confine people exclusively within basic routine activities, asking them to perform a standard of disciplinary skills, rather than producing new ones and going beyond. It becomes a kind of pre-formulated module of development which will give the necessary certification at the end. In the international healthcare sector all professional in medicine and nursing follow a learning program to ensure the maintenance and development of the professional skills, just called CPD. A comparative study, Peck et al. (2000), compares the use of CPD in Canada, United States, Europe and Australia and highlights the common elements and difference.

A second approach can be defined "organized", in other words it is characterized by the explicit planning of a consistent learning program in line with the indications given by the relevant organizational context or in some cases by the scientific community. Compared to the previous path it is not connected to legal aspects and certifications. In this case, CPD is closely linked to the strategies of the Human Resource Development 
(HRD) and, converging individual needs and position requirements, a skill development process is defined in line with the strategies and the expectations of the belonging organization. A particular attention is paid to the transfer of knowledge in the workplace and at the same time, the workplace must provide continuing learning opportunities to the people. The characteristic of this second approach is given by the close correlation between personal professional expectations and business development prospects. In the organization an effective people strategy, a strategic thinking applied to the development of human resources in line with the organizational strategies is put into practice, in which CPD can be considered a tool in supporting management and professional development with an eye on the future.

Finally, the third approach, called "personalized", presents CPD as an opportunity for individual growth which is less bounded to organizational needs but, nevertheless, related to a specific working context. Compared to the previous approaches, this one could seem less systematic and continuing, leaving more possibilities to the participant to design the process and to redefine the objectives to achieve. This method finds more application possibilities during the internship of post-graduate participants, where the practitioner is facing the professional integration and role integration with the support of a project designed by a third party in addition to the company and the employee. This process requires a definition of the own initial competences and the planning of the learning process with a possible redesign of the module in case of need, in order to respond in an appropriate way to the expectations of the participant and the organizational context. The development of a personalized CPD implies as specific characteristic the presence of a third party who is involved in the negotiation between participant and company, in order that the skill development process allows sufficient time for the training and not just the time convenient to the organization. The places with similar characteristics that carry out this function between worker and organization are the placement services of the universities or colleges, the employment centres of the provinces/districts, the vocational education centres. As regards the CPD apply to the professional development of teachers, research of Istitute of Learning higlights that shows that the key to success is when CPD mirrors the learning of others, including students and trainees, what is good practice for one is good practice for the other. Effective CPD is not an end in itself but fundamental to the sustained, positive teaching and continuous improvement of teachers and trainers, sector organisations and brilliant success for learners. A project of continuing professional development is considered a learning action during the work placement and a socialization process with the professional context and role when a real and proper apprenticeship is provided that turns knowledge into competencies. During this period, the new entrants, through a continuing internship or during the professional integration, activate their knowledge and skills linking them to the specific working context in order to develop the appropriate skills requested by the daily activities in the workplace. It is a challenging time where the willingness to learn of the employees and the commitment of the company to provide learning opportunities are at the top, aiming at the achievement of the fixed objectives.

In the school context, the process of construction of the professional identity of a teacher has the aim to increase the capacity to reflect on the experience, analyze the practices, and deepen the theoretical models. Specifically, learning how to learn, to make the best decisions in school situations. To make all this happen some essential pedagogicaldidactical approaches are needed to favour the start of the learning/teaching processes. Initiate the CPD from university education can encourage the formation of beliefs, pedagogic and didactic skills centred on the identity teacher.

An important but largely neglected factor is teachers' own beliefs, which are the best indicators of the decisions individuals make throughout their lives. Beliefs are critical 
guides of thought and behaviour (Borg, 2001), as well as filters through which people screen new knowledge and experiences for meaning. Teachers' beliefs about learning and teaching have often been subjects of research; they relate closely to the instructional decisions that teachers make (de Vries et al., 2012).

\section{AN APPLICATION FOR INTERNSHIP OF DEGREE COURSE IN PRIMARY EDUCATION}

The steps of a professional development process concerns we take some illustrative indications from the model provided by C. Abrutyn and L. Danielson and used by P.G. Rossi for the definition of portfolio (Rossi, 2005). The model consists of four stages/phases that represent the cycle of development of the portfolio according to a logic that does not limit a one-off application but with a regular procedure and method. The starting point is the model developed by Danielson and Abrutyn that articulates the process in four phases: a) Collection, defining the criteria to identify artefacts related to the objective and the participant; b) Selection, selecting the materials, specifying the criteria for the selection of the materials that meet the educational goals fixed for the portfolio; c) Reflection, including reflections in each section of the portfolio and a global reflection; d) Projection, revising periodically materials and reflections on learning included in the portfolio to verify the achieved goals and those to achieve. The model is characterized by the integration of the four phases of the process. During the first phase it is decided how and from which source selecting the material, the second phase involves the selection of the material, in the third phase reflection and self-assessment are activated, as well as in the fourth phase can be identified with the analysis of the achieved goals and the definition of the objectives to achieve. These phases can be applied during the structuring phase of the CPD, broadening the perspective beyond the evaluation. In particular, the CPD process consists of 4 macro-phases (V. Cross, C. Liles, J. Conduit \& J. Price, 2004) and it starts with an initial briefing that includes the period of time where tutor and trainee know each other, the contract agreement and the definition of the competency standards. The initial period is crucial for the prosecution of the process. It's the moment to develop a relationship built on trust and respect and to recognize the roles and the mutual commitments to achieve the goals. This specific stage/phase provides for the Educational Agreement and the Start of the process with a look to the standards related to the role and the competences to achieve. These references will become central elements even during the intermediate and final evaluation.

The second macro-phase, Collection, highlights the importance of the active role of the participant who has the commitment to record the significant events in his personal diary (log or blog) that may occur after the work placement. Since the CPD scheme is characterized by continuing learning, the following phases can become cyclical and can be proposed after a certain time interval. The evidences recorded in the personal diary will refer to the first professional experiences, in case of newly hired or interns, or will mainly focus on critical events during the following training periods.

The third macro-phase is defined Selection with the purpose of focusing the attention on specific events related to the professional experience which are significant in the sense of acquiring skills. In particular, it is meant to select some (for instance three) events among the ones reported in the personal diary where the trainee has carried out some activities relevant to his professional role. The next step (Analysis) requires the analysis of the selected material starting from the competency standards that were defined in the initial phase.

The macro-phase called Debriefing is the moment where with the support of mediation and analysis tools a critical reflection on the performance is made. That moment represents the starting point of the effective learning process. The reflection on the 
performance, the definition of the analysis methods and the determination of the development goals represent the kick-off of the process that changes the competencies and plans the next phases. In this phase the materials are linked in a network in order to describe the change, a new knowledge, the attention towards the constituent elements of a task or work activity (Rossi e al. 2012)

Subsequently the critical reflection aims to identify areas of improvement, the problematic issues, the involved professional issues, the priorities and emergencies, converging towards a shared definition of the core problem.

Through problem solving techniques, that help to perceive the discomfort and the symptoms, the real problem can be focused and the participant is invited to reflect upon the critical situations and the committed mistakes. Once identified the problem, the required working practices and the skills to achieve must be investigated. According to the method of scaffolding, the tutor (as well as the participant and his peer) supports the reflection with appropriate stimulus that help the understanding from another point of view, with more distance and a different knowledge not known to the participant up until that moment. The process continues with the definition of the goal that focuses on the work activities to achieve and to become good practices in the workplace. At that point, it is necessary to assess the required skills for the application of the new practices by identifying the sources, the offer and the activities that allow the evolution of knowledge. The phase at the end of the process starts off the cyclical process of project work. This tool allows the planning of learning activities, starting from the working activities to achieve and the skills that are considered necessary. The articulation of project work highlights the correlation between the detected problem and new expected working activities in terms of monitoring systems.

The phases are the result of the interlacing of the methods of reflective practice, of the learning from and through experience and of the planning of changes in the working context. In CPD these factors are well documented with the help of many tools that support the learning process. The monitoring of the learning projects becomes an opportunity to verify the steps taken during the execution of the project, to modify the schedule in case of insuperable problems and to set new goals in the continuing professional development. In order to find a different way of working on the development of the skills of teachers we decided to experiment in the process of training of the degree in primary education model of CPD applied to school. This will follow two different approaches: the first will involve students who for the first time will do the traineeship and they will build an educational agreement starting according to the more traditional approach of the CPD. The goal of this planning is to define a personal project work that will be useful for their professional life. With this approach we aim to form immediately in students the aptitude to reflect on the knowledge and skills for each year acquire in their degree course and that will be needed to teach. The second approach will be done with the final year students to develop an educational agreement starting from competency standards gained in degree course and starting a critical reflection during the debriefing for planning the most effective and useful project work with any objectives to be achieved. In the latter case, the aim is to allow students to reflect on the critical aspects of their professionality, their professional weaknesses to plan training courses and selftraining to fill up any professional gaps. This double work will be carried out through times of classroom teaching but also through the use of an online platform that students have avalaible for networked working with each other and with the tutors.

Fig. 1 - CPD for students of Primary education degree 


\begin{tabular}{|c|c|c|}
\hline Briefing & $\begin{array}{c}\text { Educational } \\
\text { Agreement }\end{array}$ & $\begin{array}{l}\text { Period of time where tutor and participant know each other and sign } \\
\text { a learning contract (Educational Agreement). It is the moment to } \\
\text { develop a relationship built on trust and respect, to recognize the } \\
\text { roles and the mutual commitments to achieve the goals. } \\
\text { Collecting of internal and external material that allows the } \\
\text { definition of the standards competency of the role. The material can } \\
\text { be placed in a personal folder with all the material that will } \\
\text { document the professional development }\end{array}$ \\
\hline \multirow{2}{*}{ Collection } & $\begin{array}{l}\text { Personal log } \\
\text { (Blog) }\end{array}$ & $\begin{array}{l}\text { Recording the significant events related to the workplace (both } \\
\text { positive and negative) aimed at the increase of practical experience } \\
\text { and related to a certain period in the personal diary }\end{array}$ \\
\hline & $\begin{array}{l}\text { Inner contradiction } \\
\text { and problems }\end{array}$ & $\begin{array}{l}\text { Evidencing problems and contradictions or adopted good practices } \\
\text { and connecting a representative object to the event, integrating the } \\
\text { material in the personal folder }\end{array}$ \\
\hline \multirow{2}{*}{ Selection } & Selection & $\begin{array}{l}\text { Selecting three particularly significant events from the list based on } \\
\text { personal experiences and the priorities of the role. }\end{array}$ \\
\hline & Analysis & $\begin{array}{l}\text { Identifying and reporting the facts (evidences) for each of the } \\
\text { events that practically describe what happened. }\end{array}$ \\
\hline Debriefing & Critical reflection & $\begin{array}{l}\text { Analysing activities with the support of mediation tools, such as } \\
\text { concept maps, models of organizational analysis, flow charts and } \\
\text { identifying the core problem of the critical issue. } \\
\text { Searching for solutions, formulating the work activities to achieve } \\
\text { and identifying areas to improve related to skills development. }\end{array}$ \\
\hline Planning & Project work & $\begin{array}{l}\text { Defining the project's objective and goals in terms of learning and } \\
\text { planning of the project work. Assessing the resources in terms of } \\
\text { skills, sources, social network. } \\
\text { Planning the schedule and the rate of efficiency }\end{array}$ \\
\hline
\end{tabular}

Source: reworking

\section{CONCLUSIONS}

Propose again a scientific reflection and an experimental initiative in a different context has the aim to resume an importante job for a different kind to develop teacher skills. In fact we repeat that introduce at school a model of training staff in the perspective of life long learning in other contexts seem to have success stems from the belief of the authors that this different approach the teaching profession may help to improve the approach to updating and continuing education that in Italian schools it is not developed. Educate from the beginning the usefulness of a teacher form throughout the life allows you to learn about the society in which you live, the young student that need to be trained and potential practices used for their training. It will be possible achieve this only by developing in the teachers the knowledge to be professionals and growing the competence to reflect on their experience and the capacity, to analyse the practices used by other teachers and learn the ability to deepen theoretical models of these practices. That means to learn how to learn from the experience; only through these capabilities, it will be able to take appropriate decisions to problematic situations that can be found in school. The belief of the authors is that as for professionals in general for a teacher is necessary to acquire skills criticalreflective about its own being a teacher through a training process that enables them to acquire the ability to reflect critically on their educational action and teaching, both on the positive elements that characterize it but also about what is not, they represent, therefore, the need for training during their lifetime.

\section{REFERENCES}

Billett S. (2004), "Workplace participatory practices. Conceptualising workplaces as learning environments", in The Journal of Workplace Learning, vol. 16, n. 6, pp. 312324.

Bonometti S. (2013), Lavorando s'impara. Riflessioni didattiche sulla formazione esperienziale, Pensa Multimedia, Lecce-Brescia. 
Bonometti S. (2014). A cross-media environment for teacher training. In: (a cura di): Habib M. Fardoun José A. Gallud, IDEE '14 Proceedings of the 2014 Workshop on Interaction Design in Educational Environments. ACM INTERNATIONAL CONFERENCE PROCEEDINGS SERIES, New York: ACM.

Bonometti S., Refrigeri L. (2013). Continuing Professional Development: A Work Placement Opportunity For Young Graduates. In Journal Of International Scientific Publication: Educational Alternatives, vol. 11, p. 368-378.

Cross V., Liles C., Conduit J., Price J. (2004), "Linking reflective practice to evidence of competence: a workshop for allied health professionals”, in Reflective Practice, Vol. 5, n. 1, pp. 3-31.

Danielson C., Abrutyn L. (1997), An Introduction to Using Portfolios in the Classroom, Association for Supervision and Curriculum Development, Alexandria.

De Vires S., van de Grift W., Jansen E. (2013), (2013), Teachers' beliefs and continuing professional development, Journal of Educational Administration, Vol. 51 Iss: 2, pp.213 $-231$.

Ellinger A.D., Cseh M. (2007), “Contextual factors influencing the facilitation of others' learning through everyday work experiences”, in The Journal of Workplace Learning, vol. 19, pp. 435-452.

Eneström Y., Sannino A. (2010), Studies of expansive learning: Foundation, findings and future challenges, Educational Research Review, 5, 2-24.

Evans, K., Hodkinson, P., Rainbird, H. and Unwin, L. (2006) (eds), Improving Workplace Learning, London, Routledge. Eraut M. (2000), "Non-formal learning, implicit learning and tacit knowledge in professional work", in British Journal of Educational Psychology, n.70, pp. 113-136.

Eraut M. (2007), Learning from other people at work, in F. Coffield, Learning at work, in Oxford Review of Education, vol. 33, n. 4, pp. 403-422.

Fazaeli T. (2010), Foreword, in IfL, Brilliant teaching and training in FE and skills: A guide to effective CPD for teachers, trainers and leaders, Learning and Skills Improvement Service (LSIS).

Fuller A., Unwin L. (2004), "Young people as teachers and learners in the work place: challenging the noviceexpert dichotomy", in International Journal of Training and Development, n. 8:1, p. 32-42.

IfL (Istitute for Learning) (2010), IfL review of CPD. Excellence in professional development: Looking back, looking forward.

Peck C., McCall M., McLaren B., Roten T. (2000), "Continuing medical education and continuing professional development: international comparisons”, in British Medical Journal, vol. 320, pp. 432-435.

Peel D. (2005), "Dual Professionalism: facing the challenger of continuing professional development in the workplace?”, in Reflective Practice, Vol. 6, No.1, p. 123-140.

Rossi P.G. (2005), Progettare e realizzare il portfolio, Carocci, Roma. Rossi P.G., Giannandrea L., Magnoler P. (2012), “Portfolio e riflessione”, in Educational Science and Society, n. 2, pp. 192-195. 